\title{
Adsorption Kinetics of Edamame Soybean Peel Activated Carbon in Reducing the Level of Phosphate
}

\author{
Iva Rustanti Eri ${ }^{1 *}$, Namira Kholifatul Pramudinta', Demes Nurmayanti ${ }^{1}$ \\ 1 Environmental Health Department, Health Polytechnic Ministry of Health Surabaya, Pucang Jajar Tengah 56, \\ 60282, Surabaya, Indonesia \\ * Corresponding author's e-mail: ivarust.eri@poltekkesdepkes-sby.ac.id
}

\begin{abstract}
Domestic wastewater, such as detergent wastewater, causes the increase of the phosphate level that strongly contributes to eutrophication. Adsorption is a method that can be used to reduce the levels of phosphate. The natural ingredients that can be made as activated carbon include edamame soybean peel, because it contains a lot of celluloses. This research aimed to analyze the adsorption kinetics and adsorption capacity of edamame soybean peel activated carbon in reducing the phosphate levels. Adsorption was carried out with batch method with various concentrations of adsorbate ( $2 \mathrm{mg} / \mathrm{L}, 4 \mathrm{mg} / \mathrm{L}$, and $6 \mathrm{mg} / \mathrm{L}$ ) and stirring time ( 3 hours, 6 hours, 9 hours, and 12 hours). The results showed that the highest adsorption capacity was found in $6 \mathrm{mg} / \mathrm{L}$ of adsorbate concentration and 6 hours of stirring time. The results were validated by the Langmuir isotherm and pseudo-second-order adsorption kinetics model. The Langmuir isotherm indicated that adsorption occurred in monolayer. The maximum adsorption capacity was $0.43509 \mathrm{mg} / \mathrm{g}$ and the constant of adsorption kinetics was $1.5558 \mathrm{~g} / \mathrm{mg} \cdot \mathrm{min}$. Activated carbon from edamame soybean peel successfully reduced the levels of phosphate. The increase of adsorption capacity was correlated with the increasing concentration of adsorbate and stirring time until the equilibrium.
\end{abstract}

Keywords: adsorption kinetics, activated carbon, phosphate.

\section{INTRODUCTION}

Phosphate is an important nutrient for organism growth, but causes water environmental problems in high concentrations. Emissions of large amounts of phosphate into the biota through farming, mining, and the use of synthetic detergents lead to high phosphate concentrations (beyond the natural) in the soil and surface water bodies. Excess phosphate concentrations in the environment can be harmful to organisms. It may cause kidney damage and osteoporosis (Isiuku and Enyoh 2020). Eutrophication is one of the greatest environmental problems that humanity is faced with. The eutrophic condition probably makes the algae populations increase abnormally. Those algae deplete the dissolved oxygen in the water and seriously threaten the water quality and the aquatic ecological environment (Yuliani et al., 2015). Such condition also leads to the death of aquatic life, odor and increase in the pathogenic organisms.

Adsorption is one of the methods that can be applied to reduce the wastewater pollution (Chen et al. 2020). Adsorption is the accumulation or concentration of substances at a surface or interface. The adsorbing phase is termed the adsorbent, and the material being adsorbed the adsorbate. The advantages of adsorption include low cost of operation, easy availability of adsorbent sources, recovery of solute adsorbed on the adsorbent, and regeneration of the adsorbent. Adsorption is classified into two types, i.e. physical and chemical adsorption. (Cecen and Aktas 2012). The adsorption process can be carried out by using various types of adsorbents like activated carbon. Activated carbon application currently extends to several types of industrial wastewater, there are food industry, pesticides, insecticides, and detergent industry (Cecen and Aktas 2012). 
The materials that contain carbon and celluloses, such as edamame soybean peel, can be used for processing activated carbon.

Edamame (Glycine max (L) Merrill) is a soybean variant that is rich in carbon, oxygen, and nitrogen (Chen et al. 2018). Edamame has a shorter harvest period than other soybeans (Umami et al. 2014). Edamame is low in crude protein and dry matter, which causes to faster rotting. Edamame is a tropical plant that grows well in Indonesia (Purnama et al., 2018). PT Mitratani Dua Tujuh Indonesia as Indonesia's largest edamame producer generates nearly 12 tons of edamame peel under very wet conditions every day. These conditions cause the edamame peel is still not utilized at max due to difficulties in storage.

The factors that affect the adsorption process include adsorbent mass, type of adsorbate, adsorbent surface area, adsorbate concentration, $\mathrm{pH}$, stirring speed, stirring time, and temperature. Edamame soybean peel can be turned into activated carbon to be used as adsorbent (Chen et al. 2018). Activated carbon from edamame soybean peel reduce the Fe level in water until $80 \%$ with the optimum adsorbent mass of $3.349 \mathrm{~g} / \mathrm{L}$ (Wicaksono et al., 2020).

The previous research and theoretical studies on soybean peel activated carbon and phosphate mostly stopped only at the adsorption ability, so the results were not applicable yet. Several previous studies did not examine the adsorption isotherm model and its adsorption kinetics. This research aimed to determine the kinetic model and adsorption capacity of phosphate adsorption. The isotherm model and adsorption kinetics were used to determine the adsorption capacity and rate constant. The adsorption capacity was analyzed by using the Langmuir isotherm and Freundlich isotherm models. Adsorption kinetics studies were also conducted to determine the rate of adsorption using zero-order, pseudo-first-order, and pseudo-second-order equation models. Variation of stirring time was used to find the optimum time required to reach equilibrium. The variations of stirring time have been made longer to provide a greater chance of collision between adsorbent and adsorbate. The purpose of this research was to determine the most suitable adsorption kinetics model and adsorption capacity of phosphate using edamame soybean peel activated carbon to make the results more applicable.

\section{MATERIALS AND METHODS}

\section{Activated carbon production}

The research began and starting to make an activated carbon first. Firstly, edamame soybeans peel was collected, cleaned, and then dried. The dehydration process was carried out under the sunlight until dry and using an oven with $105{ }^{\circ} \mathrm{C}$ of temperature for an hour. Carbonization was carried out at $400{ }^{\circ} \mathrm{C}$ for an hour using a furnace. The obtained carbon was crushed into 100 mesh particle size and activated by soaking in $2.5 \%$ of $\mathrm{NaOH}$ for 24 hours. Activated carbon was rinsed using distilled water until the $\mathrm{pH}$ was neutral and then dried.

\section{Activated carbon characterization}

Activated carbon that has been successfully made was tested for its characterization. Characterization aimed to determine the quality of activated carbon. Characterization was carried out by analyzing the water content, ash content, Iodine number, structure, and morphology. The water content, ash content, and Iodine number were analyzed based on Indonesia National Standard 06-3730-1995 about technical activated carbon.

The water content analysis was carried out by weighing $1 \mathrm{~g}$ of activated carbon into a porcelain cup the the weight of which was known. The samples were placed into the oven at a temperature of $115^{\circ} \mathrm{C}$ for 3 hours. The samples were cooled down in a desiccator and then weighed. Calculation of the activated carbon water content was carried out using the following formula

$$
\text { Water Content }(\%)=\frac{W_{1}}{W_{2}} \times 100 \%
$$

where: $W_{1}=$ disappear weight,

$$
W_{2}=\text { initial weight }
$$

The ash content analysis was carried out by weighing $2 \mathrm{~g}$ of activated carbon from soybean peel into a porcelain cup. Activated carbon was reduced to ashes in a furnace at $\pm 800{ }^{\circ} \mathrm{C}$ for 2 hours. The samples were cooled down in a desiccator and then weighed. Calculation of the ash content of activated carbon was done using the following formula 


$$
\text { Ash Content }(\%)=\frac{W_{1}}{W_{2}} \times 100 \%
$$

where: $W_{1}=$ residual flare,

$W_{2}=$ initial weight

The Iodine number analysis was done by initially preparing the necessary reagents. A total of $0.5 \mathrm{~g}$ activated carbon from edamame soybean peel was added into $25 \mathrm{~mL}$ of $0.125 \mathrm{~N}$ Iodine solution and stirred for 15 minutes, then stored for 2 hours. The solution was filtered and then as much as $10 \mathrm{~mL}$ was pipetted and poured into an Erlenmeyer flask. The solution was titrated by sodium thiosulfate until the yellow color faded. The solution was added with $1 \%$ of starch as an indicator and titrated using sodium thiosulfate until the dark blue color became clear. Determination of the Iodine number was calculated based on the volume of sodium thiosulfate that was used in the titration.

$$
\begin{gathered}
\text { Iodine Numbers }\left(\frac{m g}{g}\right)= \\
=\frac{m L-V \times \frac{N a_{2} \mathrm{SO}_{4}}{\mathrm{NI}_{2}} \times 12.693 \times 5}{W} \times 1
\end{gathered}
$$

where: $m L=$ the volume of sample $(\mathrm{mL})$

$V=$ titration volume $(\mathrm{mL})$

$W=$ activated carbon mass $(\mathrm{g})$

The activated carbon also characterized by means of X-Ray Diffraction (XRD) and Scanning Electron Microscopy (SEM). XRD test was carried out to analyze the structural of activated carbon and the dominant minerals by observing the peaks that appeared on the diffractogram. XRD test was performed using a PANalytical X'pert PRO in long angles. The SEM test aimed to determine the surface morphology of activated carbon before and after the adsorption process. The SEM test was carried out using an FEI Inspect S50 at $2500 \times$ and $5000 \times$ zoom in.

\section{Experiment design}

The type of this research was a pure experiment with the pretest-posttest design. The subjects were randomly divided into treatment groups with three various concentration of adsorbate $(2 \mathrm{mg} / \mathrm{L}, 4 \mathrm{mg} / \mathrm{L}$, and $6 \mathrm{mg} / \mathrm{L})$. Adsorption was carried out using the batch method. As much as $250 \mathrm{~mL}$ phosphate solution on each concentration was contacted with $4 \mathrm{~g}$ of the adsorbent in a water bath shaker at $30 \mathrm{rpm}$ speed for various time intervals ( 3 hours, 6 hours, 9 hours, and 12 hours). All of the adsorption processes were carried out at $25 \pm 3{ }^{\circ} \mathrm{C}$ and $\mathrm{pH} 3$ of the solution. Each treatment was repeated twice to obtain representative results.

The results were statistically analyzed using the Two Way ANOVA test to determine the factors that affect the decreasing phosphate level, because there were two independent variables and each sample was independent. The adsorption results were also analyzed using the Langmuir and Freundlich isotherm model to determine the optimum adsorption capacity. Determination of the adsorption kinetics model and kinetics constant was carried out by approaching the zero-order, pseudo-first-order, and pseudo-second-order kinetics models.

\section{RESULTS}

\section{Activated carbon characterization}

Activated carbon has been successfully made from dried edamame soybean peel. A total of $130 \mathrm{~g}$ of dry matter soybean peel produced $25 \mathrm{~g}$ of activated carbon. The obtained activated carbon was characterized to determine its quality. The characterization tests included water content, ash content, Iodine number, XRD, and SEM. Water content, ash content, and Iodine number analysis based on Indonesia National Standard 06-3730-1995 about technical activated carbon.

Table 1 shows the results of the examination of the water content, ash content, and iodine number of edamame soybean peel activated carbon. On the basis of the results, the activated carbon of edamame soybean peel has a $0.2 \%$ of water content value, $2.8 \%$ of ash content, and $761.58 \mathrm{mg} / \mathrm{g}$

Table 1. Water content, ash content, and iodine number analysis result of edamame soybean peel activated carbon

\begin{tabular}{|l|c|c|}
\hline \multicolumn{1}{|c|}{ Parameters } & Result & Standard \\
\hline Water content $(\%)$ & 0.2 & Max. 15 \\
\hline Ash content $(\%)$ & 2.8 & Max. 10 \\
\hline lodine Number $(\mathrm{mg} / \mathrm{g})$ & 761.58 & Min. 750 \\
\hline
\end{tabular}


of Iodine number. Edamame soybean peel activated carbon was qualified by a standard based on Indonesia National Standard 06-3730-1995 about technical activated carbon.

The X-Ray Diffraction analysis was performed at $5^{\circ}-90^{\circ}$ long angles. The XRD analysis result is shown in the form of a diffractogram with several peaks and angles. The XRD test diffractogram can be seen in Figure 1.

The XRD diffractogram showed the two highest peaks at the angle of $2 \theta=29.33^{\circ}$ and $2 \theta=$ $31.83^{\circ}$. The form of edamame soybean peel activated carbon structure was irregular, which means that activated carbon was amorphous because the peaks produced in the diffractogram were blunt and sloping. Several sharp peaks indicated that a crystalline structure appeared in the activated carbon structure. There were two dominant minerals seen in the diffractogram, namely Calcite and Potassium dihydrogen phosphate.

SEM analysis aimed to determine the structure and morphology of edamame soybean peel activated carbon. SEM was carried out with $2500 \times$ and $5000 \times$ magnification. The results of SEM analysis before and after adsorption were shown in Figure 2

Figure 2 shows the SEM analysis results of edamame soybean peel activated carbon before and after the adsorption process. Several pores on the surface of the activated carbon before the adsorption process are seen in the figure. Pores were formed during carbonization at $400{ }^{\circ} \mathrm{C}$ and expanded through activation. Impurities were shown in the surface of activated carbon because of non-evaporation volatile matter during carbonization. On the surface of activated carbon after adsorption process, there were also some materials that attached. Phosphate on the water successfully bonded to

Figure 1. The diffractogram XRD result of edamame soybean peel activated carbon the activated carbon surface because of different charge and reduced the concentration in the water until the equilibrium was reached.

\section{Phosphate adsorption}

Activated carbon is an adsorbent that can be used to adsorb phosphate in water and wastewater. The activated carbon from edamame soybean peel were applied to reduce the concentration of phosphate. The data of phosphate adsorption can be seen in Table 2.

Activated carbon is an adsorbent that can be used to adsorb phosphate in water and wastewater. The differences in adsorbate concentration and stirring time resulted in the difference phosphate removal value. The highest removal of phosphate concentration, i.e. $2.89 \mathrm{mg} / \mathrm{L}$ was found in the sample that contained $6 \mathrm{mg} / \mathrm{L}$ adsorbate concentration and was stirred for 6 hours, while the lowest removal was in the sample with $2 \mathrm{mg} / \mathrm{L}$ adsorbate concentration which was stirred for 3 hours. These results indicated that different concentrations of adsorbate and stirring times would result in varying phosphate removal value. This statement was reinforced by Two way ANOVA test results of adsorbate concentration and stirring time on the average of phosphate removal in the Table 3. The result of adsorbate concentration and stirring time on the phosphate removal have a sig value $<0.05$ while the interaction between the two variables has a value of sig $>0.05$. Adsorbate concentration and stirring time affected the decrease of phosphate levels, while both interactions had no effect.

\section{Adsorption capacity}

Adsorption capacity states the amount of adsorbate that can accumulate on the surface of the adsorbent. The adsorption capacity was determined by finding the amount of phosphate that accumulated on the adsorbent surface at equilibrium. Various concentrations of adsorbate were needed to determine the optimum concentration of adsorbate in the adsorption process. The results showed that the phosphate adsorption process using activated carbon from edamame soybean peel was balanced at 6 hours of stirring time.

Table 4 presents the data needed to calculate phosphate adsorption capacity. Calculation 
a)

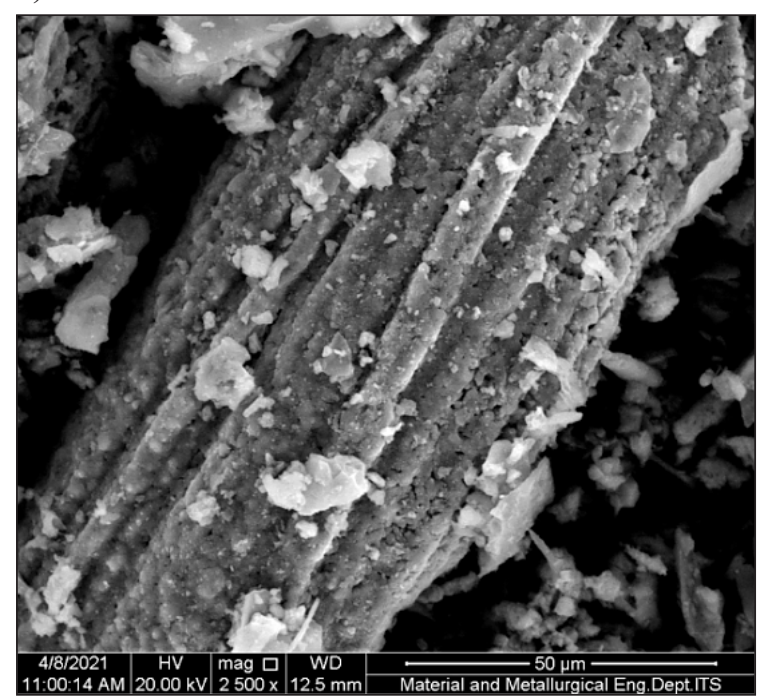

c)

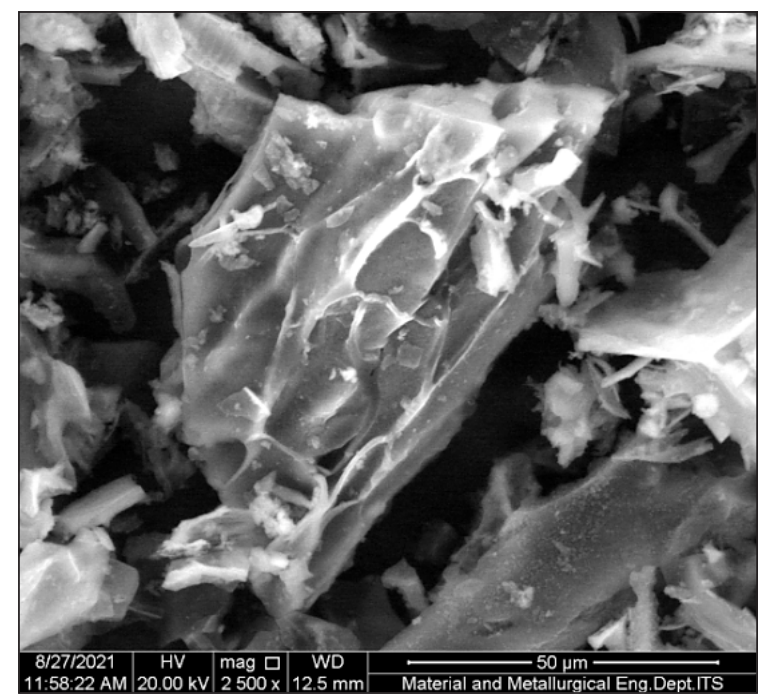

b)

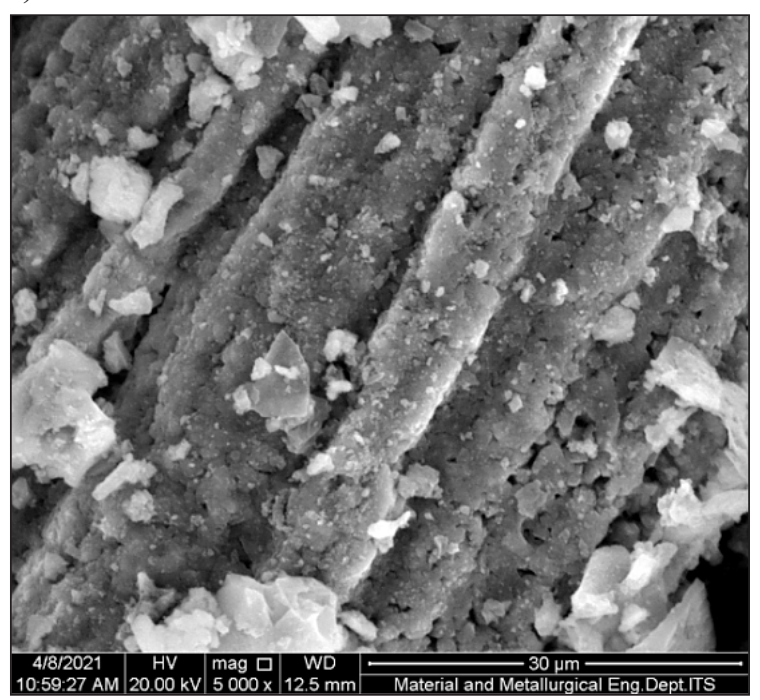

d)

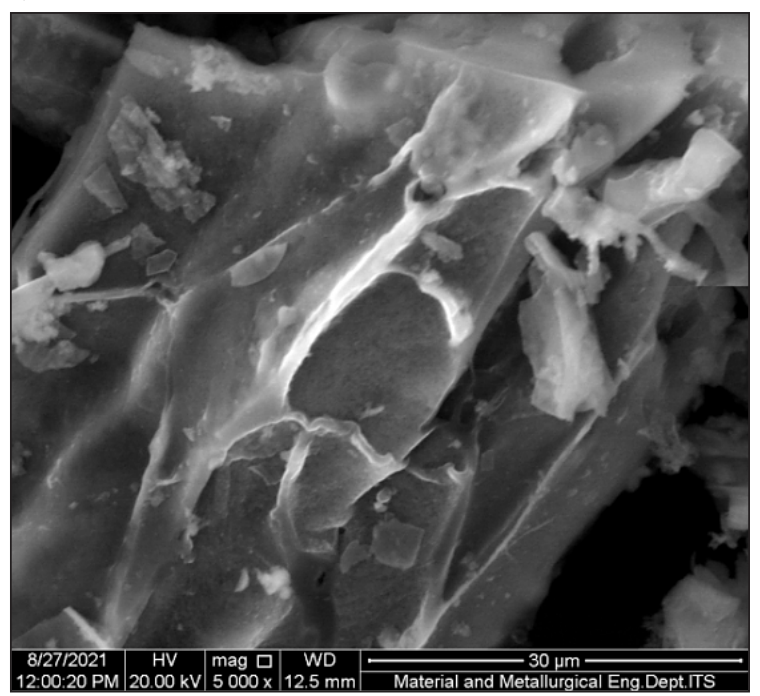

Figure 2. The SEM analysis results of edamame soybean peel activated carbon.

The result before adsorption with 2500x (a) and 5000x (b) magnification. The result after adsorption process with 2500x (c) and 5000x (d) magnification

of adsorption capacity in reducing phosphate was determined using the Langmuir isotherm and Freundlich isotherm patterns. The isotherm pattern graph of edamame soybean peel activated carbon adsorption in reducing phosphate can be seen in the following picture

Adsorption isotherm was determined by looking at the value $\left(\mathrm{R}^{2}\right)$ which is closest to 1 (linearity). The regression value $\left(\mathrm{R}^{2}\right)$ in the Langmuir isotherm pattern equation was closer to linearity with a value $\left(\mathrm{R}^{2}\right)$ of 0.9454 than the Freundlich isotherm. The maximum adsorption capacity was $0.43509 \mathrm{mg} / \mathrm{g}$. The Langmuir isotherm model assumed that the adsorption process occurred in a monolayer.
Table 2. Phosphate adsorption data

\begin{tabular}{|c|c|c|c|}
\hline Co & $\begin{array}{c}\mathrm{t} \\
\text { (hours) }\end{array}$ & $\begin{array}{c}\mathrm{Ce} \\
(\mathrm{mg} / \mathrm{L})\end{array}$ & $\begin{array}{c}\text { The average of phosphate } \\
\text { removal }(\mathrm{mg} / \mathrm{L})\end{array}$ \\
\hline \multirow{4}{*}{2} & 3 & 1.18 & 0.82 \\
\cline { 2 - 4 } & 6 & 0.60 & 1.40 \\
\cline { 2 - 4 } & 9 & 1.14 & 0.86 \\
\cline { 2 - 4 } & 12 & 1.12 & 0.88 \\
\hline \multirow{4}{*}{4} & 3 & 1.40 & 2.60 \\
\cline { 2 - 4 } & 6 & 1.18 & 2.82 \\
\cline { 2 - 4 } & 9 & 1.71 & 2.29 \\
\cline { 2 - 4 } & 12 & 1.72 & 2.28 \\
\hline \multirow{4}{*}{6} & 3 & 3.23 & 2.77 \\
\cline { 2 - 4 } & 6 & 3.11 & 2.89 \\
\cline { 2 - 4 } & 9 & 3.15 & 2.85 \\
\hline & 12 & 3.20 & 2.80 \\
\hline
\end{tabular}


Table 3. Test of between-subject effect

\begin{tabular}{|c|c|c|c|}
\hline Dependent variable & Independent variable & Mean square & Sig. \\
\hline \multirow{3}{*}{ Phosphate removal } & Adsorbate concentration & 7.677 & 0.000 \\
\cline { 2 - 4 } & Stirring time & 0.194 & 0.005 \\
\cline { 2 - 4 } & Adsorbate concentration*stirring time & 0.049 & 0.181 \\
\hline
\end{tabular}

Table 4. Adsorption capacity data

\begin{tabular}{|c|c|c|c|c|c|c|}
\hline Co $(\mathrm{mg} / \mathrm{L})$ & $\mathrm{t}$ (hours) & $\mathrm{Ce}(\mathrm{mg} / \mathrm{L})$ & $\mathrm{x} / \mathrm{m}(\mathrm{mg} / \mathrm{g})$ & $\mathrm{Ce} /(\mathrm{x} / \mathrm{m})$ & $\log \mathrm{Ce}$ & $\log (\mathrm{x} / \mathrm{m})$ \\
\hline 2 & 6 & 0.60 & 0.0875 & 6.8571 & -0.2219 & -1.0579 \\
\hline 4 & 6 & 1.18 & 0.1763 & 6.6950 & 0.0719 & -0.7539 \\
\hline 6 & 6 & 3.11 & 0.1806 & 17.2170 & 0.4928 & -0.7432 \\
\hline
\end{tabular}

\section{Adsorption kinetics}

The adsorption kinetics was determined by finding the phosphate adsorption rate with the optimum concentration using various stirring times. The value of adsorption capacity increased with the concentration of adsorbate. The optimum adsorbate concentration was $6 \mathrm{mg} / \mathrm{L}$ and the variation of stirring time was $180,360,540$, and 720 minutes. The following is data to calculate the adsorption kinetics.

The kinetics model of edamame soybean peel activated carbon adsorption in reducing levels of phosphate was determined using the kinetics equations of zero-order, pseudo-first-order, and pseudo-second-order. The value of the adsorption rate constant can be obtained based on the equation of the kinetic model with the regression value $\left(\mathrm{R}^{2}\right)$ that was closest to linearity. Zero-order, pseudo-first-order, and pseudo-second-order kinetics models of phosphate adsorption can be seen below.

a)

\section{Langmuir Isotherm Model of Phosphate Adsorption}

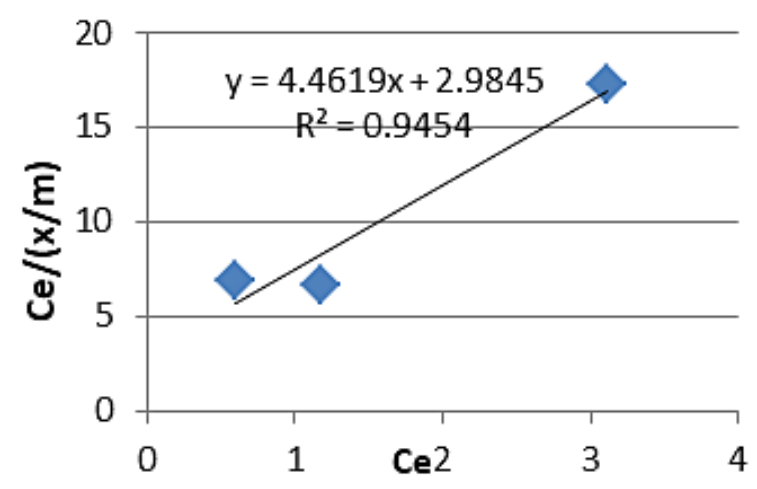

The regression coefficient $\left(\mathrm{R}^{2}\right)$ in the pseudosecond-order kinetics model has the closest value with linearity, which is 0.9992 . The adsorption kinetics of phosphate using activated carbon of edamame soybean peel followed a pseudo-second-order kinetics model with adsorption rate constant value of $\mathrm{k}=1.5558 \mathrm{~g} / \mathrm{mg} . \mathrm{min}$

\section{DISCUSSION}

\section{Activated carbon characterization}

The results of water content, ash content, and Iodine number analysis of edamame soybean peel activated carbon were $0.2 \%, 2.8 \%$, and $761.58 \mathrm{mg} / \mathrm{g}$. Water content, ash content, and Iodine number of edamame soybean peel activated carbon qualified based on Indonesia National Standard 06-3730-1995 about technical activated carbon (BSN 1995). The low value of water content and ash content was caused by the

b)

\section{Freundlich Isotherm Model of Phosphate Adsorption}

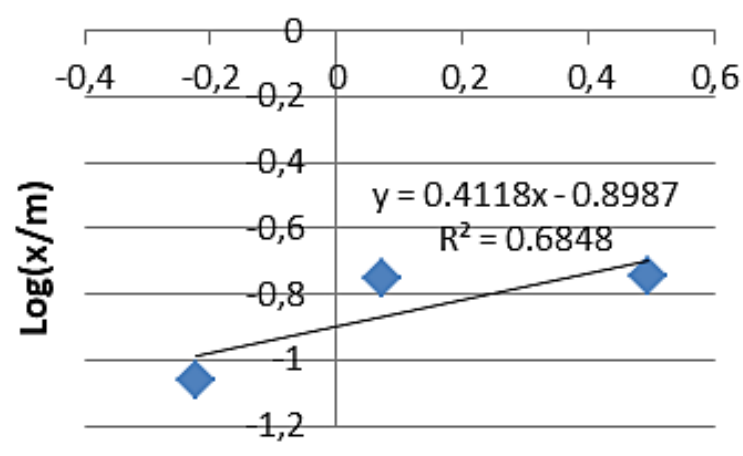

$\log \mathrm{Ce}$

Figure 3. Langmuir isotherm model (a) and Freundlich isotherm model (b) of Phosphate adsorption by edamame soybean peel activated carbon 
Table 5. Adsorption kinetics data

\begin{tabular}{|c|c|c|c|c|c|}
\hline Co $(\mathrm{mg} / \mathrm{L})$ & $\mathrm{t}$ (minutes) & $\mathrm{Ce}(\mathrm{mg} / \mathrm{L})$ & Co-Ce $(\mathrm{mg} / \mathrm{L})$ & Log $(\mathrm{Qe}-\mathrm{Qt})$ & $\mathrm{t} / \mathrm{qt}$ \\
\hline \multirow{4}{*}{6} & 180 & 3.23 & 2.77 & -2.1246 & 1039.7110 \\
\cline { 2 - 6 } & 360 & 3.11 & 2.89 & -5.3010 & 1993.0800 \\
\cline { 2 - 6 } & 540 & 3.15 & 2.85 & -5.0000 & 3031.5790 \\
\cline { 2 - 6 } & 720 & 3.20 & 2.80 & -2.2495 & 4114.2860 \\
\hline
\end{tabular}

evaporation of water content in the material during carbonization. The carbonization process succeeded in forming pores on the surface of the activated carbon (Figure 2) so that the iodine number result was above $750 \mathrm{mg} / \mathrm{g}$

The aim of the XRD test was to determine the crystalline structure of the adsorbent (activated carbon) at an angle of $2 \theta$. The results of the XRD diffractogram of edamame soybean peel activated carbon showed several peaks in the structure of activated carbon and its dominant minerals. Calcite and Potassium dihydrogen phosphate were the dominant minerals found in edamame soybean peel activated carbon. Calcite appeared at several peaks more than Potassium dihydrogen phosphate. The structure of edamame soybean peel activated carbon can be seen from the characteristics of peaks that appeared on the diffractogram. The high and low peaks produced in the diffractogram were influenced by the carbonization and activation processes during the making of activated carbon. The diffractogram image presented a graph that can be interpreted that the activated carbon has a)

Zero Order Reaction of Phosphate Adsorption Kinetics Model

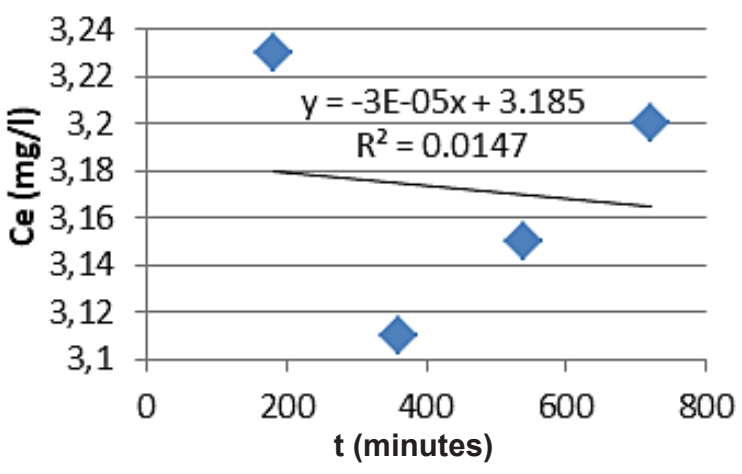

b)

\section{Pseudo First Order Reaction of Phosphate Adsorption Kinetics Model}

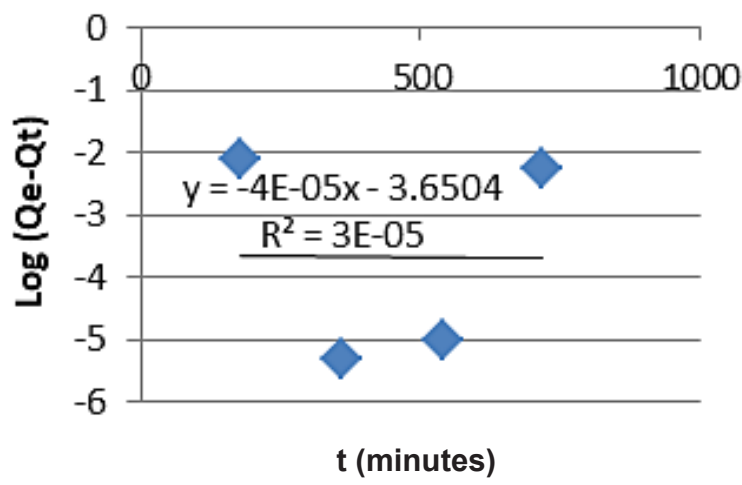

c)

\section{Pseudo Second Order Reaction of Phosphate Adsorption Kinetics Model}

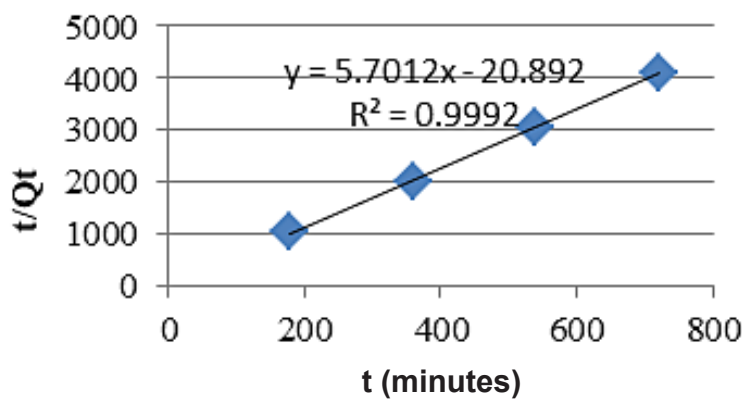

Figure 4. Zero-Order (a), Pseudo-First-Order (b), Pseudo-Second-Order (c) Kinetics model of phosphate adsorption by edamame soybean peel activated carbon 
irregular peaks that are amorphous. The amorphous form was characterized by a curve with a blunt apex and gently sloping. At the $2 \theta$ position, the activated carbon of edamame soybean peel formed a sharp hillside which approached the position of the graphite crystal structure at an angle of $2 \theta=29.33^{\circ}$ and $2 \theta=31.83^{\circ}$. This condition was caused by an unperfect carbonization process so there were some parts of the activated carbon burned at a higher temperature. Heating under $800{ }^{\circ} \mathrm{C}$ produced an amorphous (irregular) activated carbon structure, while heating at a temperature of $800-1000{ }^{\circ} \mathrm{C}$ will produce a graphite carbon structure. (Lazzarini et al. 2016).

The SEM result of edamame soybean peel activated carbon before and after adsorption process can be seen in Figure 2a and Figure 2b. The result showed that activated carbon pores have been formed. Pores were formed due to the carbonization process and expanded through activation by $\mathrm{NaOH}$. The pores on surface of activated carbon successfully bond with the phosphate on the water that made the concentration decreased. The low $\mathrm{pH}$ of water solution supports bonding between adsorbate molecule. Some impurities came from the lack of dryness raw materials and the levels of volatile substances that not perfectly evaporated when carbonization was carried out.

\section{Phosphate adsorption}

Activated carbon is an adsorbent with a wide pore surface that can absorb phosphate in water. Carbonization destroys the $\mathrm{OH}$ arrangement of celluloses that produces spaces in the structure of activated carbon. The activation process is also affected, because it increases the surface area of the activated carbon that allows adsorbate to enter the porous structure of the activated carbon. The low $\mathrm{pH}$ of water solution supports bonding between the adsorbate molecule that bonds with the negative charge of phosphate compounds and positive charge of activated carbon (Miyazato et al. 2020).

The results of phosphate levels analysis before and after the application of activated carbon can be seen in Table 2. Edamame soybean peel activated carbon reduced phosphate mostly in the sample with a $6 \mathrm{mg} / \mathrm{L}$ of adsorbate concentration which was stirred for 6 hours leaving $3.11 \mathrm{mg} / \mathrm{L}$. These results showed that the adsorbate concentration and stirring time affected the decrease in phosphate. Two way ANOVA test was conducted to determine the effect of adsorbate concentration and stirring time on the decrease of phosphate. Both variables have sig values. $<0.05$, which means that there was a difference value of average phosphate decrease by using the variation of adsorbate concentration and stirring time.

The differences in concentration and stirring time give different results in decreasing the phosphate levels. Increasing the adsorbate concentration correlated with the increase of adsorbed material on the adsorbent surface (Jain et al., 2016). Stirring time also contributed to adsorption. It was also observed that the process of adsorption is strongly affected by mixing time (Panda et al. 2017). Long stirring time provides an opportunity for collisions between the adsorbate and activated carbon, taking longer to reach equilibrium. The collision causes the adsorbate molecule to bond with the activated carbon surface so that phosphate content can be reduced. The amount of phosphate that was adsorbed will decrease with stirring time after the equilibrium phase because the surface of the adsorbent is in a saturated condition so all surfaces have been covered by adsorbate (Karthikeyan and Meenakshi 2019). It can be proven in Table 2 that the decrease of phosphate was not optimum after 6 hours of stirring in all samples with different concentrations of the adsorbate.

\section{Adsorption capacity}

Adsorption isotherm is a description of the relationship between the adsorbed substance with concentration at equilibrium and constant temperature. The most common and widely used adsorption isotherms are the Freundlich isotherm model and the Langmuir isotherm model (Cecen and Aktas 2012).

The Freundlich equation assumes that adsorption occurs in a multilayer and heterogeneous adsorbent surface. The Freundlich isotherm describes the physical adsorption that occurs in several layers and the bond is not strong. The Freundlich isotherm linear equation is obtained by plotting $\log \mathrm{x} / \mathrm{m}$ with $\log \mathrm{Ce}$, so that a straight line with a slope of $1 / \mathrm{n}$ is obtained and the intercept is equal to $\log \mathrm{k}$. Freundlich isotherm linear equation is shown in the following formula (Astya and Bachri 2020): 


$$
\log \frac{x}{m}=\frac{1}{n} \log C e+\log k
$$

where: Ce: adsorbate concentration on equilibrium $(\mathrm{mg} / \mathrm{L})$

$\mathrm{x} / \mathrm{m}$ : adsorption capacity $(\mathrm{mg} / \mathrm{g})$.

$k$ : constant

The Langmuir isotherm defines that the maximum adsorption capacity occurs due to the presence of a single layer (monolayer) of adsorbate on the adsorbent surface. The Langmuir isotherm test is done by plotting the Ce value with $\mathrm{Ce} /(\mathrm{x} / \mathrm{m})$ to obtain the linear equation. The Langmuir equation test is carried out using the following equation:

$$
\frac{C e}{x / m}=\frac{1}{a \cdot b}+\frac{1}{a} C e
$$

where: Ce: adsorbate concentration on equilibrium $(\mathrm{mg} / \mathrm{L})$.

$\mathrm{x} / \mathrm{m}$ : adsorption capacity $(\mathrm{mg} / \mathrm{g})$.

a: maximum adsorption capacity $(\mathrm{mg} / \mathrm{g})$

Adsorption capacity states the amount of adsorbate that accumulates on the surface of the adsorbent. The adsorption capacity is determined by finding the amount of phosphate that accumulates on the surface of the adsorbent at equilibrium. The increase of the average phosphate decrease and the amount of phosphate that adsorbed was proportional with the higher concentration of adsorbate. A higher concentration of adsorbate will make the amount of substance that collects on the surface of the adsorbent increase (Alghamdi et al. 2019).

The optimum concentration in this study was $6 \mathrm{mg} / \mathrm{l}$ with the highest amount of phosphate adsorbed by activated carbon of edamame soybean peel, which was $0.18063 \mathrm{mg} / \mathrm{g}$ (Table 4). The adsorption capacity of edamame soybean peel activated carbon in reducing phosphate levels followed the Langmuir isotherm pattern with the linear equation $y=$ $4.4619 x+2.9845$. From the linear equation, the maximum adsorption capacity value was $0.43509 \mathrm{mg} / \mathrm{g}$. The result was supported by Edet and Ifelebuegu, (2020) who stated that the adsorption of phosphate could be described by the Langmuir isotherm model. The Langmuir isotherm pattern defines that the maximum adsorption capacity occurs in a monolayer (Zhou et al. 2011). The active site on the surface of the adsorbent has the same ability to absorb phosphate. The adsorption process was continued only on the surface of the adsorbent that has not been covered by the adsorbate.

The process and method of carbonization are the isotherm pattern determinants in reducing the phosphate levels by activated carbon from edamame soybean peel. Carbonization produces an active site on the surface of the activated carbon which is only able to absorb the adsorbate in one layer. Relatively low iodine number also supports the result that activated carbon of edamame soybean peel for reducing phosphate follows the Langmuir isotherm model.

\section{Adsorption kinetics}

Adsorption kinetics is used to determine the rate of absorption that occurs on the adsorbent to the adsorbate that is influenced by stirring time. Zero-order kinetics assumes that increasing the concentration of reactants does not affect the magnitude of the reaction rate. Zero-order regression was obtained by plotting $\mathrm{Ce}$ (final concentration of adsorbate) with $t$ (contact time). The linear equation of zeroorder reaction is expressed in the following formula (Bulut et al., 2008):

$$
C e=C o-k t
$$

The pseudo-first-order kinetic model was derived based on the Lagergren equation. Pseudofirst-order regression is obtained by plotting log (qe-qt) with $t$ (time). The pseudo-first-order linear equation is expressed in the following formula (Zhou et al. 2011):

$$
\log (q e-q t)=\log q e-\frac{k}{2.303} t
$$

The pseudo-second-order kinetic model states that adsorption depends on the ability to adsorb each solid phase. It is assumed that the adsorption capacity is proportional to the number of active sites on the adsorbent. Pseudo-second-order regression is obtained by plotting t/qt with $t$ (contact time). The linear equation of pseudo-secondorder model is shown in the following formula (Zhou et al. 2011): 


$$
\frac{t}{q t}=\frac{t}{q e}+\frac{1}{k \cdot q e^{2}}
$$

where: $q e$ is adsorption capacity at equilibrium, $q t$ is adsorption capacity at time $\mathrm{t}$, $t$ is time,

$k$ is the constant of reaction rate.

The results showed that edamame soybean peel activated carbon in the adsorption of phosphate followed a pseudo-second-order adsorption kinetics model (Figure 4c). The determination was based on the regression value $\left(\mathrm{R}^{2}\right)$ that was closest to the linearity of 0.9992 . The results of this study are similar to the research of Isiuku et al. (2021) about phosphate ions removal by batch adsorption on activated (activation before carbonization) biochar derived from rubber pod husk that follows a pseudo-second-order kinetic model. The pseudo-second-order kinetic model defined that the adsorption speed depended on the adsorption capacity of each solid phase by the adsorbent. The concentration of adsorbate and adsorbent determined the adsorption of phosphate ions by activated carbon, so it is assumed that the adsorption capacity is directly proportional to the number of active sites in the adsorbent (Karthikeyan and Meenakshi 2019).

The linear equation on the pseudo-secondorder kinetics was $y=5.7012 x-20.892$. From this equation, the adsorption constant value of phosphate absorption using activated carbon of edamame soybean peel was $1.5558 \mathrm{~g} / \mathrm{mg} \cdot \mathrm{min}$. The results of adsorption kinetics were supported by the research of He et al. (2016) which showed that the phosphate decrease using active alkaline and zeolite followed a pseudo-second-order kinetic equation model. Impurities on the surface of activated carbon cause the absorption capacity became not good enough.

\section{CONCLUSIONS}

Edamame soybean peel can be used as activated carbon and applied as an adsorbent. Some of the characterizations on activated carbon were qualified according to Indonesia National Standard 06-3730-1995. The carbonization process succeeded in forming pores on the surface of activated carbon; thus, there are spaces for the adsorbent to bind the adsorbate. Edamame soybean peel activated carbon structure was amorphous that was characterized by a sloping peak in the XRD diffractogram result. Adsorbate concentration and stirring time affected phosphate removal. Phosphate adsorption by edamame soybean peel activated carbon followed the Langmuir isotherm model that assumed monolayer adsorption with maximum adsorption capacity was $0.43509 \mathrm{mg} / \mathrm{g}$. Phosphate adsorption also followed a pseudo-second-order kinetic model with $1.5558 \mathrm{~g} / \mathrm{mg} \cdot \mathrm{min}$ kinetic constant value. The pseudo-second-order kinetic model defined that the adsorption speed depended on the adsorption capacity of each solid phase by the adsorbent.

\section{Acknowledgments}

This research was supported by Environmental Health Department of Health Polytechnic Ministry of Health Surabaya. The authors are very grateful to the technicians of environmental health laboratory also the technicians of Materials and Metallurgical Engineering Laboratory of Institut Teknologi Sepuluh Nopember Surabaya who have helped to complete this research.

\section{REFERENCES}

1. Alghamdi A.A., et al. 2019. Efficient adsorption of lead (II) from aqueous phase solutions using polypyrrole-based activated carbon. Materials, 12(12).

2. Astya K.L., Ulinnuha S.B. 2020. The role of ampo as an adsorbent for reducing peroxide value in used cooking oil. International Seminar of Research Method, 2021, 22-29.

3. BSN. 1995. Thechnical Activated Carbon. Indonesia National Standard 06-3730-1995.

4. Bulut E., Ozacar M., Sengil A. 2008. Adsorption of malachite green onto bentonite: equilibrium and kinethics studies and process design. Microporous And Mesoporous Materials. Elsevier, 115, 234-256.

5. Cecen F., Aktas O. 2012. Activated carbon for water and wastewater treatment. Weinheim, Germany: Wiley-VCH Verlag \& Co. KGaA.

6. Chen F.F., et al. 2020. Characteristic and model of phosphate adsorption by activated carbon electrodes in capacitive deionization. Separation and Purification Technology, (November), 1-12.

7. Chen T., et al. 2018. Preparation and characterization of nitrogen and oxygen heteroatom codoped activated biocarbons from edamame shell. BioResources, 13(2), 3932-3948. 
8. Edet U.A., Ifelebuegu A.O. 2020. Kinetics, isotherms, and thermodynamic modeling of the adsorption of phosphates from model wastewater using recycled brick waste. Processes, 8(665).

9. He Y., et al. 2016. Simultaneous removal of ammonium and phosphate by alkaline-activated and lanthanum-impregnated zeolite. Chemosphere, 164, 387-395.

10. Isiuku O.B., Enyoh C.E. 2020. Pollution and health risks assessment of nitrate and phosphate concentrations in water bodies in South Eastern Nigeria. Environmental Advances, 2(August).

11. Isiuku, et al. 2021. Current research in green and sustainable chemistry phosphate ions removal from aqueous phase by batch adsorption on activated (activation before carbonization) biochar derived from Rubber pod Husk. Environmental Advances, 4(April), 100136.

12. Jain N., Dwivedi M.K., Waskle A. 2016. Adsorption of methylene blue dye from industrial effluents using coal fly ash. International Journal of Advanced Engineering Research and Science), 3(4), 9-16.

13. Karthikeyan P., Meenakshi S. 2019. Synthesis and characterization of $\mathrm{Zn}-\mathrm{Al}$ LDHs/activated carbon composite and its adsorption properties for phosphate and nitrate ions in aqueous medium. Elsevier B.V., 296.

14. Lazzarini A., et al. 2016. Graphitization of activated carbons: A molecular-level investigation by INS, DRIFT, XRD and raman techniques. Physics Procedia, 85, 20-26.
15. Miyazato T., et al. 2020. Phosphate recovery from an aqueous solution through adsorption-desorption cycle over thermally treated activated carbon. Journal of Water Process Engineering, 36, 101302.

16. Panda H., et al. 2017. Studies on adsorption behavior of an industrial waste for removal of chromium from aqueous solution. South African Journal of Chemical Engineering, 23, 132-138.

17. Purnama M.S., Cheng C.K., Nuhfil Hanani A.R. 2018. The export performance of Indonesian edamame in Japan Market. Sch. J. Econ. Bus. Manag, 5(7), 575-589.

18. Umami N., et al. 2014. The effect of planting space and harvesting period on dry matter production of Edamame Soybean straw in Samigaluh. II(November), 1361-1364.

19. Wicaksono H.A., et al. 2020. The Effectiveness of Soybean Peel Bioadsorbent (Glycine max) for Reducing Iron (Fe) Levels in Water. Environmental Health Gema, 18(2).

20. Yuliani L.R., Purwanti E., Pantiwati Y. 2015. Effect of waste laundry detergent industry against mortality and physiology index of Nile Tilapia (Oreochromis Niloticus). XII National Seminar on Biology Education FKIP UNS 822-28.

21. Zhou J., et al. 2011. Novel hollow microspheres of hierarchical Zinc-Aluminum layered double hydroxides and their enhanced adsorption capacity for phosphate in water. Journal of Hazardous Materials, 192(3), 1114-1121. 